\title{
Editorial
}

\section{The first issue of the International Journal of Research in}

\section{Marketing}

Before you lies the first issue of the International Journal of Research in Marketing (IJRM), the official journal of the European Marketing Academy. Why are we launching this new journal and what are its objectives?

Looking at the (short) history of marketing, it can be observed that, clearly, the practice of marketing management as well as marketing as a scientific discipline have their roots in the USA. There, marketing came to full bloom after World War II and, until the seventies, basic research in marketing was almost exclusively carried out in the United States. It is, therefore, not surprising that the major scientific journals in the area of marketing are found there too.

However, marketing has developed rapidly in Europe during the last ten or fifteen years. In 1975, The European Marketing Academy (EMAC) was founded. This organization now has more than 300 members, mostly from universities and business schools. These members are not only from Europe, but also from Canada, the USA, Asian countries, etc.

The increase of research activities is producing an ever growing stream of books, reports, working papers, and articles each year. One part of this work has a primarily national orientation and finds its way to national marketing journals. Another part, however, especially the more basic research, should be brought before an international forum, to be read and criticized by colleagues and to contribute to our general knowledge of market-

Intern. J. of Research in Marketing 1 (1984) 3-5

North-Holland ing. - Here lies the basic purpose of IJRM, which may be characterized as integration.

Marketing is an applied, interdisciplinary field. In the study of marketing phenomena and the solution of marketing problems, concepts and theories from different disciplines (economics, psychology, operations research, statistics) are used in different settings with respect to socio-economic and cultural conditions. Consequently, research in marketing covers a broad range of types of approach and subjects studied, depending on the discipline's main accents, the specific area of marketing (or the specific mix instrument studied) and the prevailing marketing environment.

For the further development of the body of knowledge and the identity of the marketing discipline, integration is essential. IJRM aims to integrate the results from the rich collection of theoretical and empirical contributions obtained through different approaches under different circumstances. Such integration should be in the interest both of the accumulation of more basic insights into the factors determining marketing mechanisms and marketing processes and of the acquisition of knowledge - theory and methods - relevant for decision making in marketing.

This integrative objective entails that: (a) IJRM will publish work from all different countries. As the official journal of the European Marketing Academy (EMAC), $I R J M$ will, in the first place, pay attention to research done in the various European countries. However, authors from North America, 
Asia, Australia and other parts of the world are very much encouraged to submit their articles;

(b) IJRM is open to different disciplinary approaches (behavioral, economic, statistical, quantitative, etc.) as well as to work emanating from different philosophical viewpoints. Notably, the potential synergetic effects of these different contributions will be considered. For integration both conceptual/theoretical developments and empirical work (analysis and testing) are necessary: both types of work will be published in the journal;

(c) IJRM will cover the whole area of marketing: profit as well as non-profit marketing, consumer behavior, product decisions, pricing, marketing communication, marketing channels, strategic market planning, industrial marketing, international marketing, etc. Special attention will be paid to hitherto underexposed topics such as comparative marketing, cross-cultural aspects of marketing, government and marketing, and marketing and society.

The purpose of integration is combined with the objective of high quality. IJRM wishes to publish the best work in research in marketing as it is carried out in the different subfields of marketing and, in this way, to contribute to the further development of the marketing discipline.

It will be clear from the foregoing that $I J R M$ does not intend to restrict itself to Europe. It is recognized that marketing is developing rapidly in other parts of the world also. Apart from the USA and Canada, Asian countries (e.g. Japan, the Philippines, Hong Kong) and Australia should be mentioned. This international orientation is reflected in the composition of the Editorial Board which comprises members from all these parts of the world. It is also reflected in the adjective 'international' in the name of the journal. It should be emphasized that the journal is not primarily directed towards "international marketing' (although articles on this topic will be published), but that rather 'international' refers to the international origins of the research reported.

As you can see, this orientation is illustrated by the contents of this first issue, with articles from France, Denmark, the United Kingdom, the USA, and with reviews of books from Sweden, Germany and The Netherlands.

Besides articles, IJRM has a book review section (edited by Reinhard Angelmar), which is intended to serve the purpose of disseminating information about research in marketing carried out in different countries. This section will also pay attention to publications appearing in languages other than English to make such research accessible to a broad audience.

As the Editor of $I J R M$, I wish to thank all those, who, during the nearly two years of preparation, have contributed to the inception of this journal: the members of the Fditorial Board, the additional reviewers who generally did a great job (a full list of names will be published in one of the next issues), the representatives of Elsevier Science Publishers (North-Holland) Carel A. van Houten and Ms Anna de Haas, and my secretaries Olga Hitters and Dorothée van Dooren, who very competently supported me in the handling of the papers.

In the little more than one year during which papers could be submitted, I received 75 papers. In 59 cases, a first decision was made (the other 16 are still in the first stage of the process): 31 (53\%) of the papers were rejected and in all other cases revision was required. In this issue, you will find the first six papers that were finally accepted.

I very much hope that $I J R M$ will attain its goals and, through its integrative orientation, will contribute to the body of knowledge of the marketing disciplines. This cannot be 
accomplished by the Editor or the Editorial Board alone. I hope you will send me your comments, suggestions, and criticism.

I also hope that $I J R M$ will continue to receive high-quality papers - an absolutely necessary condition for fulfilling its goals. I am at all times ready to cooperate with prospective authors; if you have writing plans but would like to discuss them first, please contact me. On the inside back cover of this issue you will find the "Instructions to authors'. All articles will be published in English. However, papers may be submitted in French or German, but after acceptance should be translated into English (which is the responsibility of the author).

I hope to hear from you.

Berend Wierenga

Editor 